\title{
PROFILE OF ANTIBACTERIAL ACTIVITY OF FRACTIONS FROM METHANOL EXTRACTS OF GARCINIA LATISSIMA MIQ. FRUIT RIND
}

\author{
NENENG SITI SILFI AMBARWATI ${ }^{1,2}$, AMARILA MALIK ${ }^{1 *}$, BERNA ELYA ${ }^{1}$, MUHAMMAD HANAFI ${ }^{3}$ \\ ${ }^{1}$ Department of Pharmacy, Faculty of Pharmacy, Universitas Indonesia, Depok, Indonesia. ${ }^{2}$ Department of Family Well-Being, Faculty \\ of Engineering, Universitas Negeri Jakarta, Jakarta, Indonesia. ${ }^{3}$ Research Centre for Chemistry, Indonesian Institute of Sciences (LIPI), \\ Tangerang, Indonesia. Email: amarila.malik@ui.ac.id \\ Received: 20 April 2017, Revised and Accepted: 13 July 2017
}

ABSTRACT

Objectives: A previous study showed that methanol extracts of Garcinia latissima Miq. demonstrated antibacterial activity against Bacillus subtilis, Staphylococcus aureus, and Pseudomonas aeruginosa. The aim of this study was to obtain active antibacterial fractions from methanol extracts of G. latissima Miq.

Methods: Fractionation of extracts was performed on G60 silica gel column chromatography using n-hexane eluent, ethyl acetate, and methanol. Antibacterial tests were done using the paper disc method to determine the zone of inhibition, the microdilution method to determine the minimum inhibitory concentration (MIC), and a bioautographic test.

Results: Fractions A-E, and F had zones of inhibition against B. subtilis. Fractions A-E had zones of inhibition against $S$. aureus. Fractions C-E had zones of inhibition against $P$. aeruginosa. The bio-autograph test showed zones of inhibition on several bio-autographic spots, indicating that active compounds were obtained from the fractionation of methanol extract from G. latissima Miq. fruit rind. Fraction D's MIC against B. subtilis, S. aureus, and P. aeruginosa was 312.5 ppm. The MIC of Fraction C against B. subtilis and of Fraction R against P. aeruginosa also was 312.5 ppm.

Conclusion: Fraction D was the most active fraction against the three test bacteria.

Keywords: Garcinia latissima Miq., Bacillus subtilis, Staphylococcus aureus, Pseudomonas aeruginosa, Zone of inhibition, Minimum inhibitory concentration, Bio-autograph.

(C) 2017 The Authors. Published by Innovare Academic Sciences PvtLtd. This is an open access article under the CC BY license (http://creativecommons. org/licenses/by/4. 0/) DOI: http://dx.doi.org/10.22159/ajpcr.2017.v10s5.23099

\section{INTRODUCTION}

Many diseases are caused by bacteria. $72 \%$ of 50 medicinal plants belonging to 26 families have been found to have antibacterial activity [1]. Based on gram staining, bacteria are classified into Gram-negative or Gram-positive bacteria, such as Pseudomonas aeruginosa [2]. Previous studies have shown that methanol extract of Garcinia latissima Miq. rind has antibacterial activity against Bacillus subtilis, Staphylococcus aureus, and P. aeruginosa [3].

Fractionation is the process of separating compounds based on their polarity. Fractionation can be done using column chromatography. Column chromatography involves liquid-solid adsorption and requires packing columns with adsorbents such as silica gel, wherein the sample is eluted using a solvent. Adsorption will stop when the concentration of a substance in solution and the mass absorbed in the stationary phase reach equilibrium [4]. The use of mixed solvents of different polarity will result in a partition mechanism [5].

Antibacterial tests can be performed by the diffusion method, which is based on the ability of a test substance to diffuse on an agar medium containing the test microbe, and the dilution method, which involves mixing the test substance with the test bacteria in a liquid medium. The bio-autographic test is also easy to use, cost-effective, fast, and able to assess the antibacterial activity of a considerable sample [6].

\section{METHODS}

Fractionation of the extract was performed using column chromatography with $300 \mathrm{~g}$ silica gel in stationary phase with $25 \mathrm{~g}$ extract samples. The motion phases of n-hexane, ethyl acetate, and methanol were used, gradually increasing the polarity. The elution results were collected in a $100-\mathrm{mL}$ bottle. The concentrate fractions have been tested used thin layer chromatography (TLC) and fractions with the same TLC profiles were combined, resulting in eight fractions.

The inhibition test of the fractions used nutrient agar medium for B. subtilis and S. aureus and cetrimide for P. aeruginosa. The fraction was dissolved in dimethyl sulfoxide (DMSO) at a concentration of 20,000 ppm. $1 \mathrm{~mL}$ of bacterial suspension with 106 microbes/mL was placed into a tube containing $4 \mathrm{~mL}$ of antibiotic media that was liquefied by heating at $45-60^{\circ} \mathrm{C}$. After being shaken with a vortex until homogeneous, solutions were poured into Petri dishes containing $20 \mathrm{~mL}$ of solid nutrient media. The Petri dish, with a top layer of seed, was shaken slowly and then allowed to freeze. 6-mm diameter sterile paper discs were placed on the Petri dishes and added with $20 \mu \mathrm{L}$ of fraction solution (triplo). Then, Petri dishes for $S$. aureus and B. subtilis were incubated at $37^{\circ} \mathrm{C}$ for $24 \mathrm{hrs}$, while P. aeruginosa was incubated at room temperature for $48 \mathrm{hrs}$. The diameter of the zone of inhibition was observed and measured using calipers [7].

The TLC bio-autographic test was performed using bilayer media [8]. Bacteria were inoculated on suitable media and then poured over solid agar medium. The eluted and dried TLC plates were attached to the agar layer and left for about $1 \mathrm{hr}$ to allow the diffusion of the compound. After the TLC plate was removed, S. aureus and B. subtilis plates were incubated at $37^{\circ} \mathrm{C}$ for $24 \mathrm{hrs}$; meanwhile, $P$. aeruginosa was incubated at room temperature for $48 \mathrm{hrs}$. The zone of inhibition indicated the presence of active compounds functioning as antibacterial agents [9].

The minimum inhibitory concentrations (MICs) of fractions were determined using the microdilution method. Fractions were dissolved 
in DMSO and diluted using bacterial media or broth. Each $50-\mu \mathrm{L}$ fraction solution was added with $50 \mu \mathrm{L}$ of inoculum containing bacteria at a concentration of $10^{6} \mathrm{CFU} / \mathrm{mL}$. From each well, the following fraction concentrations were obtained: 5,000 ppm (test), 2,500 ppm, 1,250 ppm, $625 \mathrm{ppm}, 312,5 \mathrm{ppm}, 156,25 \mathrm{ppm}$, and 78,125 ppm (triplo test). Microplates were incubated at $37^{\circ} \mathrm{C}$ for 24 hrs. Pseudomonas aeruginosa was incubated at room temperature for 48 hrs. After incubation, $0.6 \mathrm{mg} / \mathrm{mL}$ of MTT solution was added to a10- $\mu \mathrm{L}$ sterile Aqua dest [9] and then incubated for 20 minutes. Observations were performed visually by looking for the presence or the absence of discoloration. The presence of bacterial growth is characterized by a change in color from light yellow to purple or pink. The lowest concentration of non-discolored wells is the MIC [10].

\section{RESULTS AND DISCUSSION}

Fractionation results are presented in Table 1. Fraction $\mathrm{F}$ was the largest fraction, followed by Fraction E.

The first antibacterial test was the zone of inhibition test for the six resulting fractions of $G$. latissima Miq rind extract. The results are shown in Table 2.

The zone of inhibition test showed that all fractions were active against $B$. subtilis and $S$. aureus, except Fraction F, which did not show activity against $S$. aureus. Fractions C-E were active against $P$. aeruginosa. Although the concentration of fractions used for all tests was similar $(20,000 \mathrm{ppm})$, the number of antibacterial agents diffusing on the agar surface was unknown. This is one deficiency of the zone of inhibition method, so this method is not appropriate for establishing MICs. A bio-autographic test was performed on the active fractions from the zone of inhibition test. The test results are shown in Figs. 1-3. The red circles indicated the presence of an inhibition area of bacterial growth resulting from the fraction eluted during TLC. The motion phases used in TLC were n-hexane:ethyl acetate (8:1) for Fraction A, dichloromethane:methanol

Table 1: Fractionation results from methanol extracts of G. latissima Miq. fruit rind

\begin{tabular}{llll}
\hline Fraction & Bottle number & $\begin{array}{l}\text { Fraction } \\
\text { weight }(\mathbf{g})\end{array}$ & \% Fraction \\
\hline A & $1-42$ & 0.1825 & 13.1492 \\
B & $43-70$ & 0.0812 & 0.5850 \\
C & $71-77$ & 0.2085 & 1.5022 \\
D & $78-84$ & 0.4414 & 3.1903 \\
E & $85-112$ & 3.6210 & 26.0894 \\
F & $113-148$ & 9.3446 & 67.328 \\
& Total weight of fraction & 13.8792 & \\
\hline
\end{tabular}

G. latissima: Garcinia latissima

Table 2: Zone of inhibition results from 20,000 ppm methanol fractions of G. latissima rind

\begin{tabular}{llll}
\hline Fraction & \multicolumn{3}{l}{ Diameter of zone of inhibition $(\mathbf{m m})$ of bacteria } \\
\cline { 2 - 4 } & B. subtilis & P. aeruginosa & S. aureus \\
\hline A & $6.747 \pm 0.237$ & 0.000 & $7.700 \pm 0.400$ \\
B & $7.110 \pm 0.608$ & 0.000 & $7.867 \pm 0.379$ \\
C & $8.140 \pm 0.078$ & $6.167 \pm 0.058$ & $6.800 \pm 0.200$ \\
D & $8.243 \pm 0.645$ & $6.933 \pm 0.058$ & $6.633 \pm 0.379$ \\
E & $7.903 \pm 0.291$ & $6.167 \pm 0.058$ & $6.367 \pm 0.208$ \\
F & $7.017 \pm 0.770$ & 0.000 & 0.000 \\
Antibiotic & $29.175 \pm 0.983$ & $14.250 \pm 0.693$ & $24.855 \pm 0.021$ \\
standard & & & \\
Negative & 0 & 0 & 0 \\
control & & & \\
\hline
\end{tabular}

B. subtilis: Bacillus subtilis, P. aeruginosa: Pseudomonas aeruginosa S. aureus: Staphylococcus aureus
(8:1) for Fraction B, dichloromethane:methanol (8:1) for Fraction C, n-hexane:chloroform:ethyl acetate (1:1:2) for Fraction D, dichloromethane:methanol (6:1) for Fraction E, and dichloromethane:methanol $(6: 1)$ for Fraction F.

The presence of zones of inhibition indicated active compounds in the tested fractions. From the bio-autographic test results, semi-polar compounds were able to create a zone of inhibitions.

Antibacterial tests were also performed using the microdilution method for calculating the MIC. The results are shown in Table 3.

The results provided in Table 3 showed that the Fraction D of methanol extract from the fruit rind of G. latissima Miq had moderate activity against $B$. subtilis, $S$. aureus, and P. aeruginosa, with MIC values of 312.5 ppm. Fraction $\mathrm{C}$ against $B$. subtilis and Fraction E against $P$. aeruginosa had similar MIC values, which were $312.5 \mathrm{ppm}$. Fractions B and $\mathrm{E}$ had weak activity against $B$. subtilis, with MIC values of $625 \mathrm{ppm}$. Fractions A-C, and E also had weak activity against $S$. aureus, with MIC values of $625 \mathrm{ppm}$. Fractions B and $\mathrm{C}$, and $\mathrm{F}$ had weak activity against $P$. aeruginosa with MIC values of $625 \mathrm{ppm}$. Fraction A was not active against $B$. subtilis and $P$. aeruginosa because the MIC values were $1.250 \mathrm{ppm}$. Fraction $\mathrm{F}$ was also not active against $B$. subtilis and $S$. aureus because the MIC values were $1.250 \mathrm{ppm}$.

These values were in accordance with the MIC reference values for antimicrobial activity. If $<100 \mathrm{ppm}$, the antimicrobial activity is strong. If the MIC value is between 100 and $500 \mathrm{ppm}$, antimicrobial activity is moderate. An MIC value between 500 and $1,000 \mathrm{ppm}$ is weak, while more than $1,000 \mathrm{ppm}$ indicates inactivity in terms of antimicrobial activity [11]. The antimicrobial activity of these tested fractions was compared with standard drugs, including erythromycin for B. subtilis and gentamicin for P. aeruginosa. The results of this study indicated that one fraction from the methanol extract of $G$. latissima Miq. rind that exhibited moderate activity in inhibiting the growth of $B$. subtilis, $S$. aureus, and P. aeruginosa bacteria.

\section{CONCLUSION}

Fraction D was the most active fraction of the three tested bacteria. The MIC test of fractions from ethyl acetate of G. latissima Miq. rind can be further explored through isolating active fractions, which could play an important role in the discovery of new medicines. Further studies are needed, including a toxicity test, to purify active compounds from G. latissima fractions with potential use as antibacterial agents in the pharmaceutical industry.

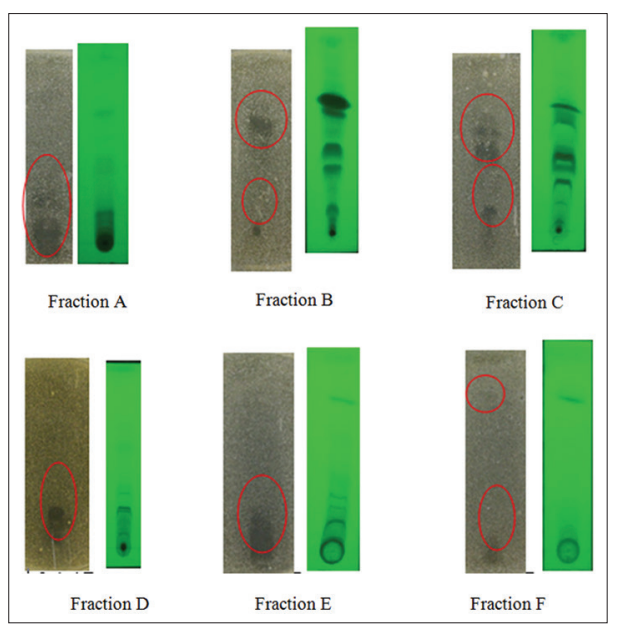

Fig. 1: Bio-autographic results of active fractions from Garcinia latissima Miq. rind methanol extract against Bacillus subtilis 


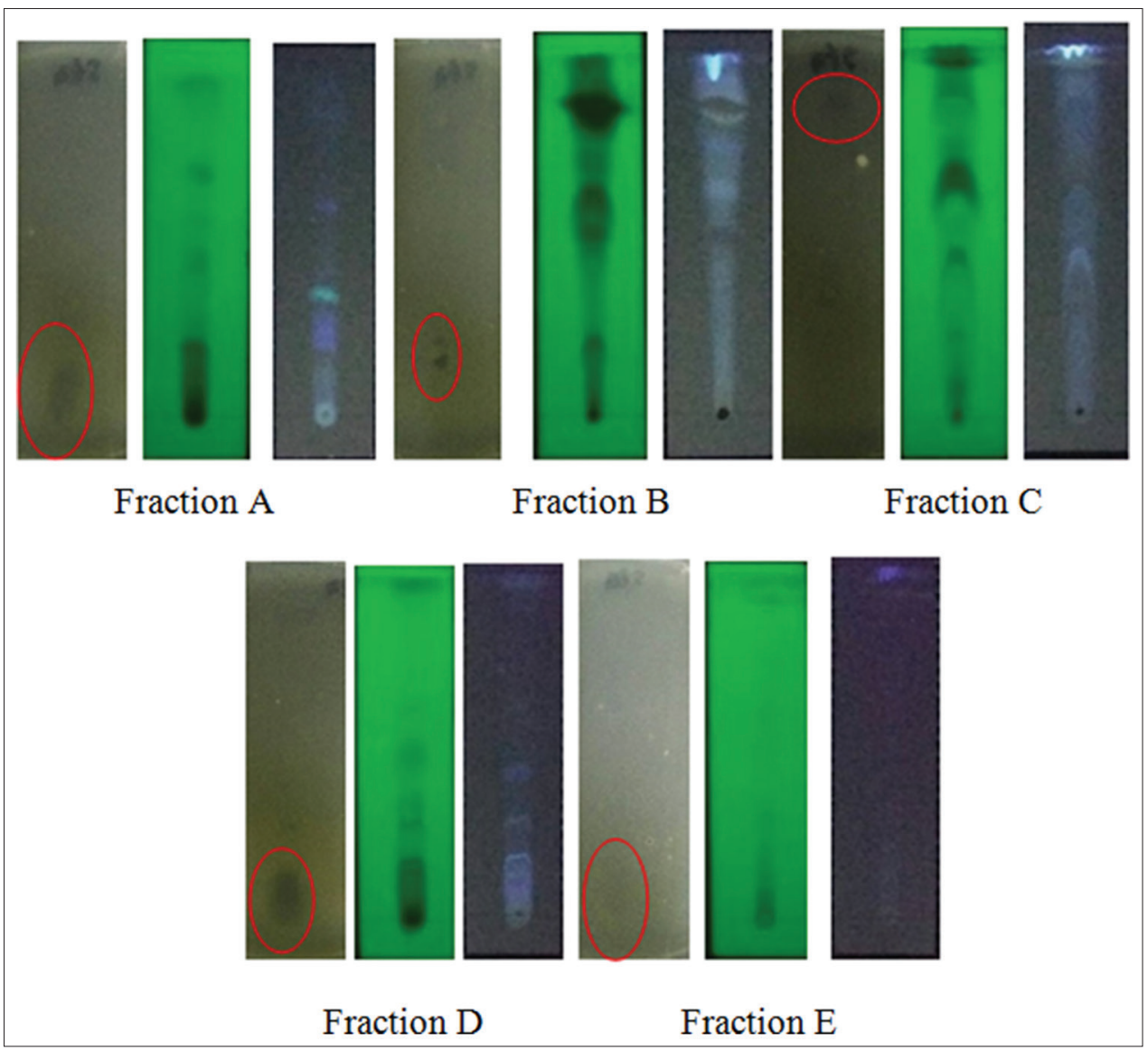

Fig. 2: Bio-autographic results of active fractions from Garcinia latissima Miq. rind methanol extract against Staphylococcus aureus

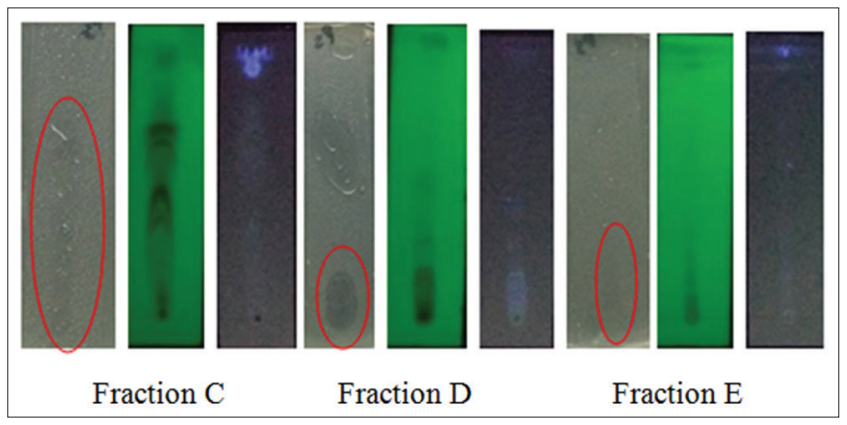

Fig. 3: Bio-autographic results of active fractions from Garcinia latissima Miq. rind methanol extract against Pseudomonas aeruginosa

Table 3: MIC results of fractions from G. latissima Miq. rind methanol

\begin{tabular}{llll}
\hline Fraction & B. subtilis & S. aureus & P. aeruginosa \\
\hline A & 1.250 & 625 & 1.250 \\
B & 625 & 625 & 625 \\
C & 312.5 & 625 & 625 \\
D & 312.5 & 312,5 & 312.5 \\
E & 625 & 625 & 312.5 \\
F & 1.250 & 1.250 & 625 \\
Antibiotic standards & 25 & & 0.39 \\
\hline
\end{tabular}

G. latissima: Garcinia latissima, MIC: Minimum inhibitory concentration,

B. subtilis: Bacillus subtilis, P. aeruginosa: Pseudomonas aeruginosa,

S. aureus: Staphylococcus aureus

\section{ACKNOWLEDGMENTS}

The author gratefully acknowledges the PITTA grant 2017 received from the Universitas Indonesia in financial support of this work.

\section{REFERENCES}

1. Srinivasan D, Nathan S, Suresh T, Lakshmana Perumalsamy P. Antimicrobial activity of certain Indian medicinal plants used in folkloric medicine. J Ethnopharmacol 2001;74(3):217-20.

2. Jawetz E, Melnick JL, Adelberg EA, Carroll KC. Jawetz, Melnick \& Adelberg's Medical Microbiology. $27^{\text {th }}$ ed. New York: Mc Graw Hill Education; 2016

3. Ambarwati NS, Elya1 B, Malik A, Hanafi M. Phytochemical and antimicrobial studies on garcinia latissima miq. fruits extract. Asian J Pharm Clin Res 2017;7(10):230-2

4. Ahuja S. Chromatography and Separation Science, Separation Science and Technology. Vol. 4. California: Elsevier Science; 2003.

5. Reid RG, Sarker SD. Isolationof natural products by low-pressure column chromatography. In: Sarker SD, Nahar L, editors. Natural Product Isolation Methods and Protocols. New York: Humana Press;2012. p. 155-87. Available from: http://www.books.google.com/books?id=Ku2wPAAACAAJ.

6. Sarker SD, Latif Z, Gray AI. Natural Products Isolation. $2^{\text {nd }}$ ed. New Jersey: Humana Press; 2006.

7. Kochuthressia KP, Britto SJ, Raphael RJ. In vitro antimicrobial evaluation of Kaempferia galanga L. Rhizome extract. Am J Biotechnol Mol Sci 2012;2(1):1-5. Available from: http://www.scihub.org/AJBMS/ PDF/2012/1/AJBMS-2-1-1-5.pdf.

8. Dewanjee S, Gangopadhyay M, Bhattacharya N, Khanra R, Dua TK. Bioautography and its scope in the field of natural product chemistry. J Pharm Anal 2015;5(2):75-84. Available from: http://www.dx.doi. org/10.1016/j.jpha.2014.06.002.

9. Messi BB, Ho R, Meli Lannang A, Cressend D, Perron K, Nkengfack AE, et al. Isolation and biological activity of compounds from Garcinia preussii. Pharm Biol 2014;52(6):706-11. Available from: http://www.ncbi.nlm.nih.gov/pubmed/24824323.

10. Zubair M, Rizwan K, Rasool N, Afshan N, Shahid M, Ahmed VU, et al. Antimicrobial potential of various extract and fractions of leaves of Solanum nigrum. Int J Phytomed 2011;3(1):63-7.

11. Fernandes MR, Souza CR, Oliveira VA, Dias LT, Carvalho RR. Antioxidant and antimicrobial activities of Psidium guajava L. spray dried extracts. Ind Crops Prod 2014;60:39-44. Available from: http:// www.linkinghub.elsevier.com/retrieve/pii/S0926669014003288. 